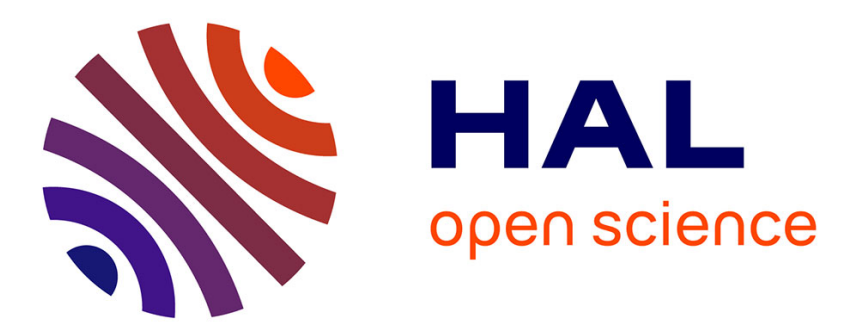

\title{
Wavelet analysis of experimental blade vibrations during interaction with an abradable coating
}

Romain Mandard, Jean-François Witz, Yannick Desplanques, Jacky Fabis, Jean Meriaux

\section{- To cite this version:}

Romain Mandard, Jean-François Witz, Yannick Desplanques, Jacky Fabis, Jean Meriaux. Wavelet analysis of experimental blade vibrations during interaction with an abradable coating. Journal of Tribology, 2014, 136, pp.31102. 10.1115/1.4027438 . hal-01089112

\section{HAL Id: hal-01089112 \\ https://hal.science/hal-01089112}

Submitted on 1 Dec 2014

HAL is a multi-disciplinary open access archive for the deposit and dissemination of scientific research documents, whether they are published or not. The documents may come from teaching and research institutions in France or abroad, or from public or private research centers.
L'archive ouverte pluridisciplinaire HAL, est destinée au dépôt et à la diffusion de documents scientifiques de niveau recherche, publiés ou non, émanant des établissements d'enseignement et de recherche français ou étrangers, des laboratoires publics ou privés. 


\title{
Wavelet analysis of experimental blade vibrations during interaction with an abradable coating
}

\author{
Romain MANDARD ${ }^{1,2,3,5}$, Jean-François WItz ${ }^{1,3}$, Yannick DeSPLANQUES ${ }^{1,2,3}$, Jacky FABIS ${ }^{4}$, \\ and Jean MERIAUX ${ }^{5}$ \\ ${ }^{1}$ Univ Lille Nord de France, F-59000 Lille, France \\ ${ }^{2}$ EC Lille, LML, F-59650 Villeneuve d'Ascq, France \\ ${ }^{3}$ CNRS, UMR 8107, F-59650 Villeneuve d'Ascq, France \\ ${ }^{4}$ ONERA, The French Aerospace Lab, F-59000 Lille, France \\ ${ }^{5}$ SNECMA, site de Villaroche, F-77550 Moissy-Cramayel, France
}

\begin{abstract}
Minimizing the clearance between turbofan blades and the surrounding casing is a key factor to achieving compressor efficiency. The deposition of an abradable coating on casings is one of the technologies used to reduce this blade-casing clearance and ensure blade integrity in the event of blade-casing contact. Aircraft in-service conditions may lead to interactions between the blade tip and the coated casing, during which wear of the abradable coating, blade dynamics and interacting force are critical yet little-understood issues. In order to study blade/abradable-coating interactions of a few tens of milliseconds, experiments were conducted on a dedicated test rig. The experimental data were analyzed with the aim of determining the friction-induced vibrational modes of the blade. This involved a time-frequency analysis of the experimental blade strain using the Continuous Wavelet Transform, combined with a modal analysis of the blade. The latter was carried out with two kinds of kinematic boundary conditions at the blade tip: free and modified, by imposing contact with the abradable coating. The interaction data show that the blade vibration modes identified during interactions correspond to the free boundary condition, due to the transitional nature of the phenomena and the very short duration of contacts. The properties of the Continous Wavelet Transform were then used to identify the occurence of blade-coating contact. Two kinds of blade/abradable-coating interactions were identified: bouncing of the blade over short time periods associated with loss of abradable material, and isolated contacts capable of amplifying the blade vibrations without causing significant wear of the abradable coating. The results obtained were corroborated by high-speed imaging of the interactions.
\end{abstract}




\section{Nomenclature}

\begin{tabular}{ll}
\hline APA & Amplified Piezoelectric Actuator \\
CWT & Continuous Wavelet Transform \\
$D_{N}$ & Apparent incursion of the blade $(\mu \mathrm{m})$ \\
$f_{c}$ & Blade bounce frequency $(\mathrm{Hz})$ \\
$f_{k}$ & Fourier frequency corresponding to wavelet scale $s_{k}(\mathrm{~Hz})$ \\
$f_{n}, n \in \mathbb{N}$ & Blade natural frequency $(\mathrm{Hz})$ \\
FFT & Fast Fourier Transform \\
$N$ & Signal size \\
$p$ & Wavelet parameter \\
$s_{0}$ & Smallest resolvable scale $(\mathrm{s})$ \\
$s_{k}$ & $k^{\text {th }}$ wavelet scale $(\mathrm{s})$ \\
$\mathrm{STFT}$ & Short-Time Fourier Transform \\
$V_{T}$ & Blade/abradable-coating relative tangential speed $(\mathrm{m} / \mathrm{s})$ \\
$X\left(\eta, s_{k}\right)$ & Function of two variables defining the Continuous Wavelet Transform \\
$\delta s$ & Scale parameter \\
$\delta t$ & Sampling period $(\mu \mathrm{s})$ \\
$\eta$ & Nondimensional time parameter \\
$\psi$ & Mother wavelet \\
$\psi^{*}$ & Complex conjugate of $\psi$ \\
$\varepsilon_{x x}$ & Blade longitudinal strain $(\mu \mathrm{m} / \mathrm{m})$ \\
\hline
\end{tabular}




\section{Introduction}

The efficiency of turbojet engines is directly affected by the clearance between rotating blades and stationary casing. Minimizing the in-service clearance to a few tenths of millimeters has been shown to reduce leakage flows and consequently improve efficiency, and may well be critical to engine integrity. During engine operation, the rotor-stator interface is subjected to centrifugal rotor loadings, differential thermal expansions between the rotor and the stator as well as accelerations arising from aircraft maneuvering and vibrations. The relative rotor-stator displacements that are induced may lead to zero clearance and critical blade-casing interactions. One of the technologies used to achieve a compromise between compressor performance and blade mechanical integrity is the deposition of an abradable coating on the casing. In the event of blade-casing contact, the blade tip abrades the coating, which has been designed to be easily worn. Nevertheless, repeated contacts may cause severe abradable coating wear, blade fatigue and the development of blade cracks. Such phenomena have indeed been encountered in full-scale experiments such as those performed by Millecamps et al. [1]. The authors have underlined the association between the excited bending modes of the blade and the wear profile of the abradable coating. Their experiment, which was conducted until blade failure, demonstrated the predominance and divergence of the first bending mode. Experimental knowledge of wear mechanisms, blade dynamics and interacting force is paramount to the proper design of abradable materials and the prediction of their lifetimes through numerical simulations.

Different kinds of test rigs have been developed to study the interactions between blades and abradable coatings, with different levels of in-service representativeness, especially with regard to the relative speed between the two. In the compressor stages of engines, maximum blade tip speeds are on the order of 500 $\mathrm{m} / \mathrm{s}$. Sutter et al. [2] and Cuny et al. [3] devised specific setups for identifying the interaction force and wear mechanisms pertaining to abradable materials (AlSi-Polyester) for relative speeds of up to $100 \mathrm{~m} . \mathrm{s}^{-1}$ and $270 \mathrm{~m} \cdot \mathrm{s}^{-1}$, respectively. In these experiments, a gas gun was used to launch an abradable sample into interaction with a cutting tool made of steel or titanium alloy. Stringer and Marshall [4] and Fois et al. [5] investigated the wear rates and mechanisms between an abradable AlSi-hBN coating and a rotating titanium blade for relative velocities of $100 \mathrm{~m} \cdot \mathrm{s}^{-1}$ to $200 \mathrm{~m} \cdot \mathrm{s}^{-1}$. The experiments developed by Padova et al. [6] and at Sulzer-Innotec $[8,9]$ are sufficiently representative of full-scale tangential speeds (up to $400 \mathrm{~m} \cdot \mathrm{s}^{-1}$ ). Most of these experiments use small rigid blades that allow precise control of incursion depths and speeds $[4,5,8,9]$. However, they do not take into consideration the blade dynamics. In the experiment by Padova et al. $[6,7]$, the blades were instrumented with strain gauges and the vibratory responses were analyzed using the conventional Fast Fourier Transform. However, the analysis does not investigate the connections between blade vibrations and abradable coating wear, which have been reported to be potentially critical to engine integrity [1]. Although the experiments covered in the present paper were conducted at a low tangential speed $\left(19 \mathrm{~m} . \mathrm{s}^{-1}\right)$ that is not reflective of true engine speeds, they did involve the use of appropriate instrumentation and data processing techniques to investigate the abovementioned connections.

The present work is based on an experimental approach initiated by Baïz et al. [10], in which a test rig was developed to reproduce blade-coating interactions of a few tens of milliseconds. The rig was designed to allow blade displacement measurement, strain measurement and high-speed imaging for the analysis of couplings between blade vibration and abradable coating wear. Blade-casing contact is usually studied over several blade revolutions, either experimentally or through numerical simulations $[11,12]$. The characterization of abradable wear also tends to be performed after either a few [7] or many [5] blade rubs. In terms of abradable-wear mechanisms, the quoted studies are clearly more representative of the full-scale situation than the short-duration interactions reported by Baïz et al. in [10]. The present paper provides a complementary approach to that, with the aim of understanding how blades are excited and abradable coatings are worn by a single rub. 
Baïz et al. conducted experiments with an abradable AlSi-hBN coating, which is currently used in compressor stages of many aircraft engines. This material comprises an aluminium-silicon matrix (AlSi) and an hexagonal boron nitride phase $(\mathrm{hBN})$ that acts as a dislocator [13]. The raw data from these experiments are presented in [10]. The objective of this paper is to provide a new interpretation of these data by means of time-frequency analysis. To do so, it was necessary to localize contacts and identify frequencies involved during interactions. It was important to understand these interactions before proposing a model of blade-casing contact and estimating the force at the blade tip. This interacting force, which is key feature of blade-casing contact, is not easily obtained. This is particulary true in the case of slender blades that are commonly found in the compressor section of engines, where direct force measurements are tricky owing to the vibrations in this area. Non-intrusive instrumentation for force measurement may likewise be difficult to install. However, the combination of indirect measurements and an analytical model, as previously proposed by Krajcin and Söffker [14], constitutes a relevant method that supports the present paper as an upstream investigation of interacting force.

More specifically, our paper aims to provide a time-frequency decomposition of the dynamic interactions. Indeed, to our knowledge, very few authors have proposed time-frequency representations that enable the identification of active vibrational modes and contact occurences $[15,16]$. Two complementary approaches have been employed: a modal analysis of the test rig and a decomposition of the blade dynamics in the timefrequency domain using the Continuous Wavelet Transform, combined with the Fast Fourier Transform. The combination of these two approaches enabled the identification of excited vibrational modes and contact occurences. High-speed imaging of the interaction confirmed the connections between blade/abradablecoating rubbing and blade vibrations.

\section{Blade/abradable-coating interaction experiments}

\subsection{Test rig}

As the design and instrumentation of the test rig have been fully detailed in [10], this section aims to highlight its main features and present the raw data that will be used in the following. The setup was designed to reproduce blade/abradable-coating interactions. In order to simplify the dynamic measurements, the rig configuration was modified with respect to the full-scale configuration, as shown in figure 1. In engines, blades have complex geometries and undergo rotary motion (Fig. 1a). The test platform consists of a rotating cylinder (300 mm-diameter) whose external surface is coated with an abradable material. The blade geometry has been simplified and the interaction generated by translating the blade toward the rotating cylinder (Fig. 1b).

Curvature reversal is the main difference between engine and test-rig configurations. However, the two radii of curvature are on the same order of magnitude (several hundred millimeters), which is twice that of the blade tip tickness ( 1 to $2 \mathrm{~mm}$ ). On the scale of the blade tip, this curvature reversal is not expected to modify the behavior of the abradable coating, and the only differences should lie in the number and duration of blade rubs within an incursion, depending on the blade-coating relative speed. Another difference is the centrifugal stiffening of blades in the full-scale configuration [15]. However, in the test rig configuration, the geometry of the non-rotating blade can be adjusted to be equivalent (in terms of natural frequencies) to a blade stiffened by a centrifugal loading. Such a reversed configuration was used in the study by Laverty [17], in order to facilitate the measurement of contact forces and blade temperatures, during continuous rubbing between an abradable coating and a rigid blade. In the quoted study, the abradable material was deposited on the outer surface of a $127 \mathrm{~mm}$-diameter rotating disk. 


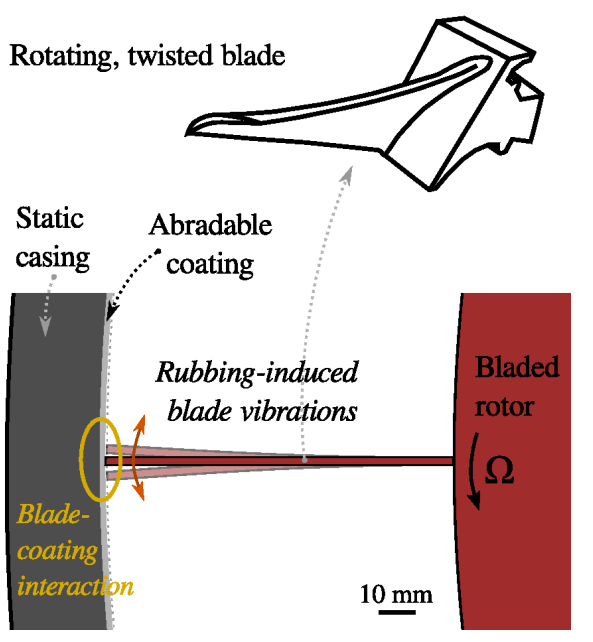

(a)

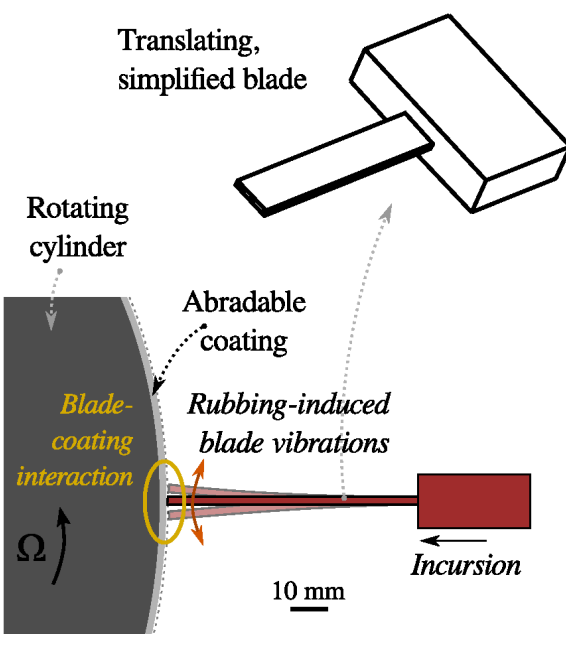

(b)

Figure 1: Schematic representation of blade/abradable-coating interaction a) actual compressor configuration and b) reverse test-rig configuration.

Figure 2 shows the incursion cell of the test rig. The relative tangential speed $V_{T}$ is created by spinning the coated cylinder. A titanium blade (TA6V alloy) is fastened to a small rigid unit, which is moved toward the abradable coating in direction $x$ by means of an Amplified Piezoelectric Actuator (APA) [18]. The displacement of the small rigid unit, $D_{N}$, is defined as the apparent incursion of the blade. The APA actuator was chosen as it is capable of achieving relatively large strokes (several hundreds of micrometers) while being reasonably sized. However, this type of actuator has low stiffness. During short-duration interactions (corresponding to high-frequency command of the actuator), $D_{N}$ can be influenced by blade-coating contact as well as resonance. Thus, incursions are generated by an electrical pulse (selected in terms of shape, amplitude and duration) sent to the actuator.

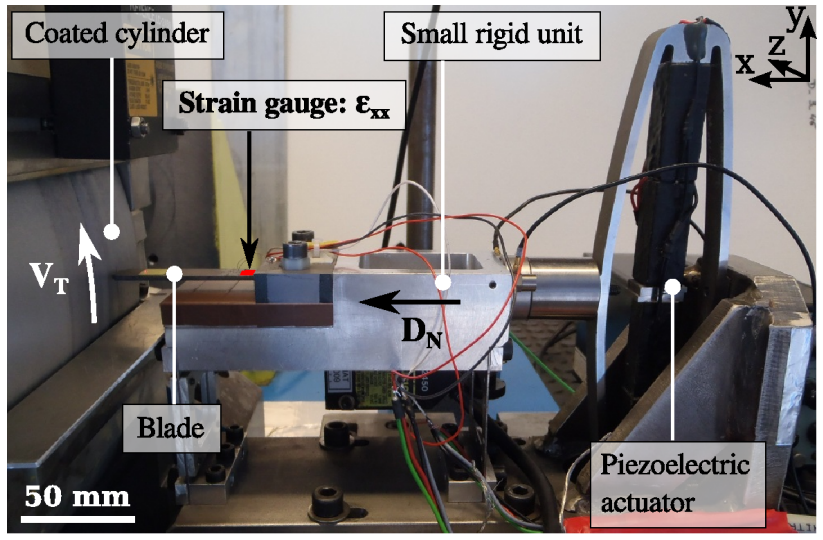

a)

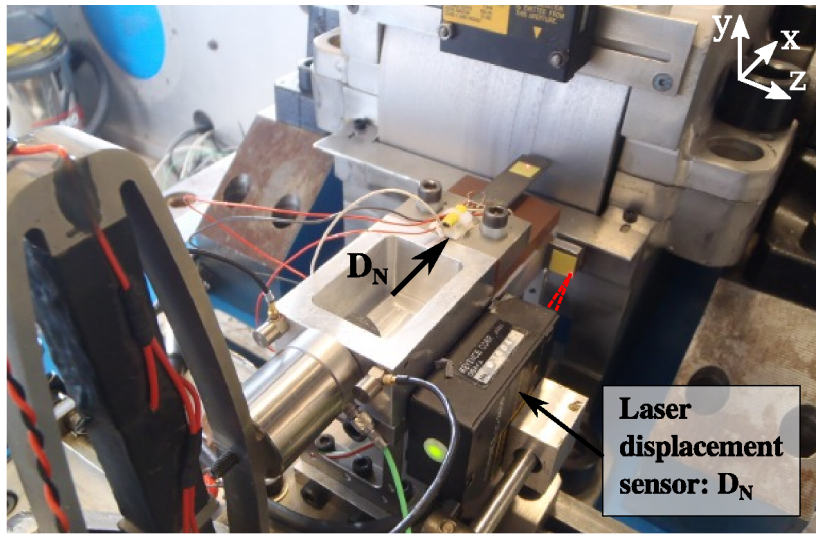

b)

Figure 2: a) Side view and b) top view of the incursion cell of the test rig. 
The actual displacement $D_{N}$ is measured and controlled during the interaction via a laser displacement sensor (Fig. 2b). In most studies on blade/abradable-coating contact [2, 3, 4, 5, 8, 9], the normal displacement of the blade root or cutting tool can be considered to be a penetration of the blade tip/tool into the abradable coating because the blades/tools are very stiff. However, as the present study focuses on blade vibrations, the apparent incursion $D_{N}$ (displacement of the blade root) cannot be described as such.

The blade design was reduced to a rectangular cross-section in order to better study the bending dynamics; three such blades with different characteristics were made. The blades dimensions are summarized in Table 1. An analytical calculation of the dynamic characteristics (natural frequencies, modal stiffness and mass) was carried out by Baïz et al. [10], based on the Euler-Bernoulli beam model with a clamped-free boundary condition. The instrumentation used in [10] includes a strain gauge bonded at a distance of $5 \mathrm{~mm}$ from the clamped end. The measured strain, $\varepsilon_{x x}$, is the longitudinal strain in the direction of blade incursion $x$, and is the sum of the compressive and bending strains. However, on account of the simplified blade geometry, $\varepsilon_{x x}$ consists mainly of the bending component. A simplified test was performed to consider the feasibility of measuring blade compression by means of two strain gauges bonded on opposite sides of the blade ( $\varepsilon_{x x}^{\text {top }}$ and $\left.\varepsilon_{x x}^{b o t .}\right)$. The compressive strain was calculated as follows: $\varepsilon_{x x}^{\text {comp }}=0.5\left(\varepsilon_{x x}^{t o p}+\varepsilon_{x x}^{\text {bot. }}\right)$. A normal impact with an amplitude and duration representative of a blade-coating impact was applied at the blade tip by means of an impact hammer. In this simple test case, $\varepsilon_{x x}^{\text {comp }}$ was found to reach $40 \mu \mathrm{m} / \mathrm{m}$. This is less than $1 \%$ of maximum blade strain measured in the three experiments and is also lower than the strain noise, which was on the order of $50 \mu \mathrm{m} / \mathrm{m}$. For these reasons, the blade strain signals presented in this paper were considered to be bending strains to a first approximation.

\begin{tabular}{llll}
\hline \multicolumn{4}{l}{ Dimensions in mm } \\
\hline & Blade a & Blade b & Blade c \\
\hline Length & 60 & 60 & 45 \\
Width & 10 & 10 & 10 \\
Thickness & 2 & 1.2 & 1.2 \\
\hline
\end{tabular}

Table 1: Dimensions of the blades.

\subsection{Experimental data}

In order to make relevant conclusions on blade dynamics, three experiments involving different blades, with $V_{T}=19 \mathrm{~m} . \mathrm{s}^{-1}$, were analyzed. As shown in Table 1, the blades have different thickness. Although the influence of varying blade tip thickness and geometries on contact modification is not covered in this paper, it has been known to affect the nature of abradable wear debris and mechanisms $[19,8]$. The raw measurements of the apparent incursion $D_{N}$ and blade strain $\varepsilon_{x x}$ for experiments 1 (blade a), 2 (blade b) and 3 (blade c) are plotted in Fig. 3, 4 and 5, respectively. Each interaction experiment can be divided into two phases. The first phase corresponds to the period when the command was relayed to the actuator. The shape of the apparent incursion during phase one is a combination of the modal characteristics of the incursion cell, the profile of the applied voltage and the contact force. In experiments 2 and 3, actuator resonance was used to generate three subincursions. Previously, incursions without blade-coating interaction were tested in order to set the appropriate input voltage signal. 

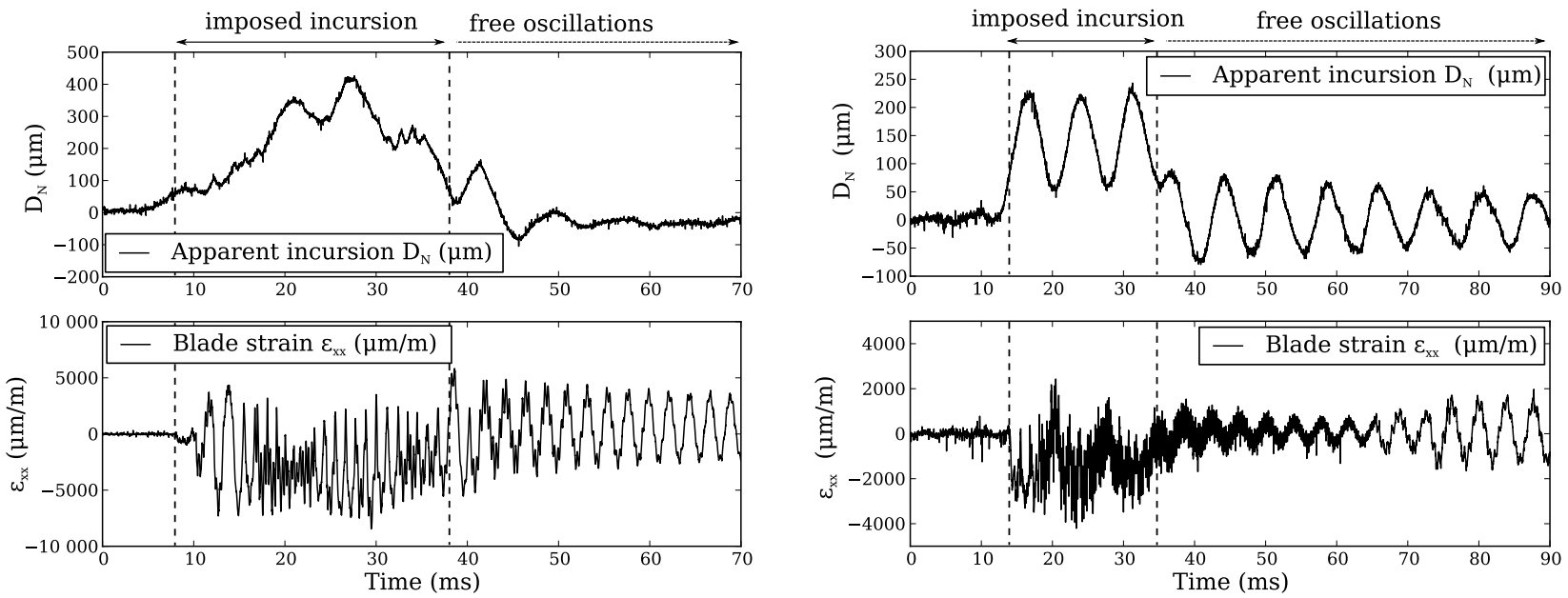

Figure 3: Raw signals obtained in experiment 1 (blade a).

Figure 4: Raw signals obtained in experiment 2 (blade b).

In the first phase, the maximum apparent incursion of the blade was $420 \mu \mathrm{m}$ for experiment 1,230 $\mu \mathrm{m}$ for experiment 2 and $210 \mu \mathrm{m}$ for experiment 3. The second phase corresponds to the free-oscillation stage experienced by the incursion cell, i.e. when no voltage was applied to the actuator. Both the apparent incursion $D_{N}$ and blade strain $\varepsilon_{x x}$ indicate the presence of free oscillations. The oscillations of displacement $D_{N}$, which were of appreciable amplitude (up to $100 \mu \mathrm{m}$ in experiment 3), were responsible for isolated blade-coating contact within phase two. Baïz et al. [10] conducted a preliminary investigation of the dynamic coupling during such isolated contact, and we propose to take this further by means of a complementary and more robust analysis.
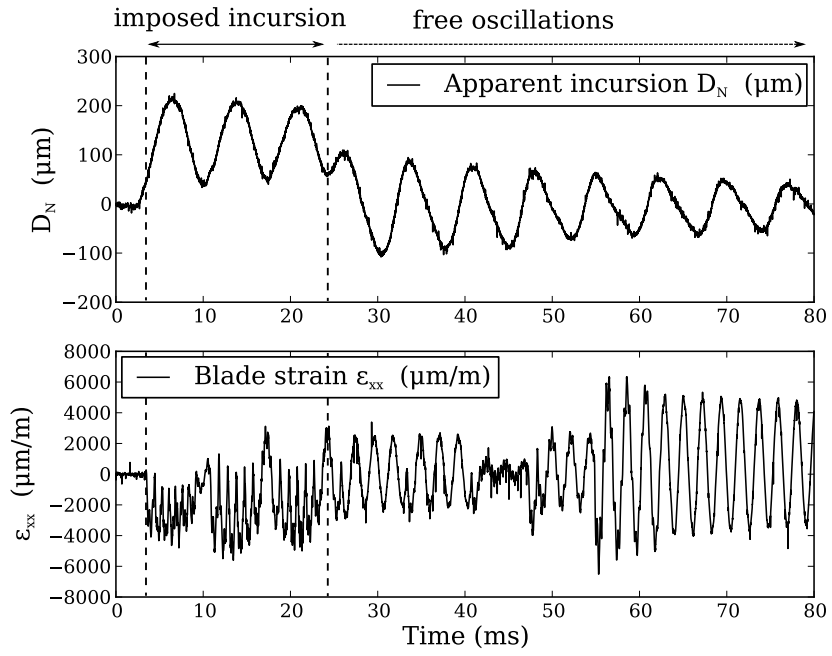

Figure 5: Raw signals obtained in experiment 3 (blade c). 


\section{Modal analysis of the incursion cell}

\subsection{Methodology}

Dynamic measurements are inevitably linked to the dynamics of the test rig - either those of the tested components (the blade in our case) or a dynamic contribution of the actuation or measurement system. Therefore, we must determine the natural modes of the tribometer in order to clearly interpret the raw data. The purpose of this section is to identify the translational and rotational modes of the incursion cell that are likely to influence blade-coating interaction, as shown in Fig. 6. A modal analysis of the complete incursion cell (Fig. 6) was performed with blade a mounted on the small rigid unit and a free boundary condition at the blade tip. An experimental modal analysis of blades a and $b$ was carried out, with two different boundary conditions that were assumed to be representative of the blade-coating interactions.

The blades and the incursion cell were meshed with a sufficient number of points (21 each) to reconstruct the mode shapes. The mesh is shown in Fig. 6 for visible points in this view. Mesh points correspond to the locations of frequency response functions (FRF). The structure was excited in directions $x$ and $y$ with an impact hammer, with a single excitation point for each direction. Vibratory responses were measured at each point of the mesh with a laser vibrometer on the blade (velocity measurement) and an accelerometer on the small rigid unit (acceleration measurement). The mode shapes and natural frequencies were computed using a Time-MDOF algorithm (Least Square Complex Exponential) within the [0-10 kHz] frequency band.

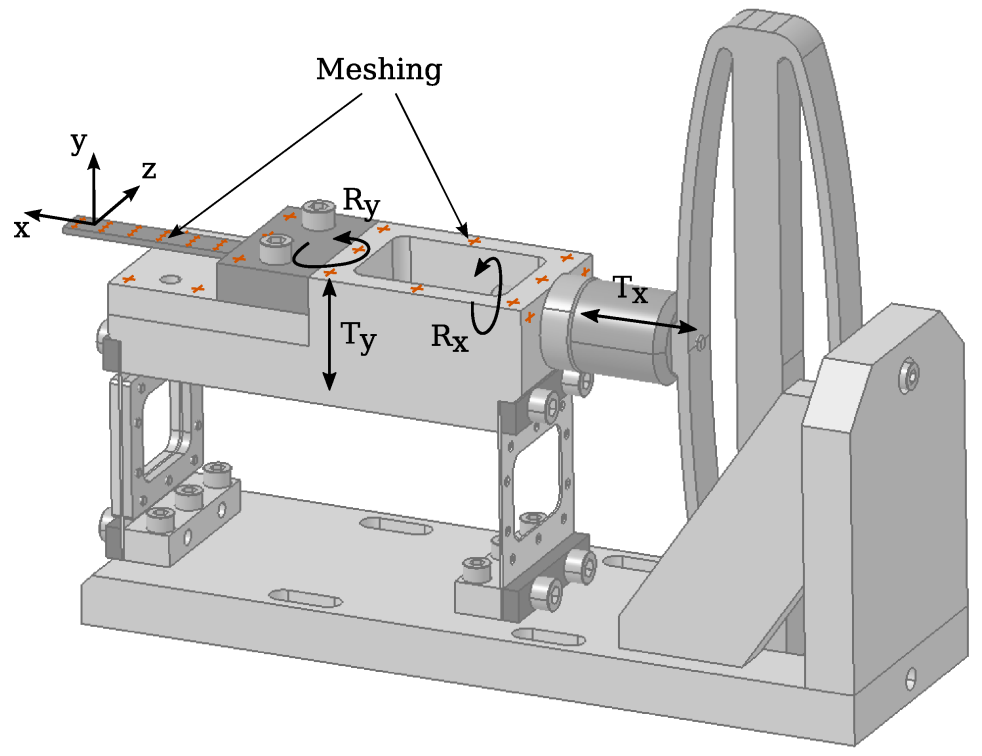

Figure 6: Experimental modal analysis of the incursion cell: meshing and directions of natural modes.

\subsection{Natural modes of the incursion cell}

The natural modes of the incursion cell are listed in Table 2. $T_{x}^{1}(150 \mathrm{~Hz})$ and $T_{x}^{2}(280 \mathrm{~Hz})$ are two translational modes in the direction of incursion, whose contribution is visible in the displacement $D_{N}$ measured in experiments 2 and 3 (Fig. 4 and 5, respectively), during the free oscillations. As mentionned in section 2.2, the $T_{x}^{1}$-resonance of the actuator was used to generate the three subincursions (imposed incursion period). 


\begin{tabular}{ll} 
Mode & Frequency $(\mathrm{Hz})$ \\
\hline$T_{x}^{1}$ & 150 \\
$T_{x}^{2}$ & 280 \\
$R_{y}$ & 860 \\
$T_{y}$ & 1400 \\
$R_{x}$ & 2200 \\
\hline
\end{tabular}

Table 2: Experimentally identified natural modes of the incursion cell.

In the modal analysis, the presence of two translational modes in direction $x$ is consistent with the findings of Olympio and Poulin-Vittrant [20], whose work on the amplified piezoelectric actuator (APA) clearly indicates the presence of two mode shapes arising from the two flexural arms of the actuator. Three other modes - two rotational, $R_{y}$ and $R_{x}$, and one translational, $T_{y}$ - were identified. It should be noted that the natural modes listed in Table 2 are only marginaly affected $(<0.5 \%$ in frequency) when changing the blade.

\subsection{Natural modes of the blade}

During the experiments presented in [7] and [10], short periods of alternating contact were observed. The assumption of alternating kinematic boundary conditions during blade-coating interaction is therefore plausible. An experimental modal analysis of the blades was conducted with two different sets of boundary conditions: clamped-free and clamped-simply supported. The clamped-simply supported boundary conditions is assumed to be representative of the contact between the blade tip and the abradable coating. The mathematical description of these boundary conditions is zero bending displacement and zero bending moment at the blade tip. Fig. 7 shows the corresponding experimental setup. In order to mimic real conditions as closely as possible, the contact condition was achieved with a sample of abradable AlSi-hBN material on the bottom edge of the blade tip (unilateral contact). Low energy impacts were produced with the hammer in order to avoid any blade bouncing on the abradable sample that could modify the boundary condition. The validity of this experimental boundary condition was verified by examining the extracted mode shapes.

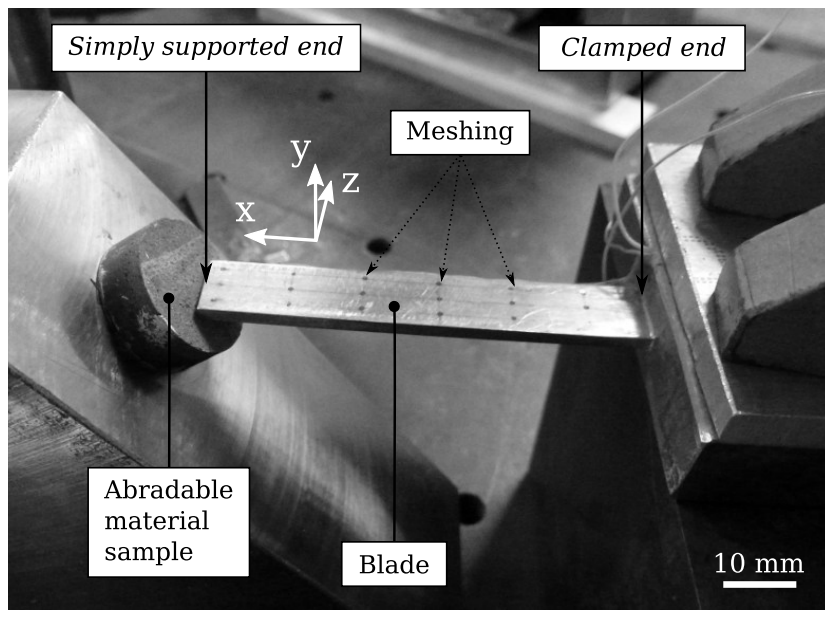

Figure 7: Experimental set up for the modal analysis of the clamped-simply supported blade. 
The experimental bending modes of blades $\mathrm{a}$ and $\mathrm{b}$ are listed in Table 3. For the clamped-free boundary conditions, the experimental frequencies are in agreement with the theoretical values obtained using the Euler-Bernoulli beam model and given in Table 4, within a 4\% error range. Regarding the clamped-simply supported boundary condition, experimental and theoretical frequencies are in agreement within an error range of $3 \%$ for the two first modes and $10 \%$ for the third. It should be reminded that the beam was excited with an impact hammer and that the FRF coherence was acceptable (i.e. $>0.75$ ) within the $[0-10 \mathrm{kHz}]$ frequency band.

\begin{tabular}{|c|c|c|}
\hline \multirow[t]{2}{*}{ Mode } & \multicolumn{2}{|c|}{ Frequency $(\mathrm{Hz})$} \\
\hline & Blade a & Blade b \\
\hline \multicolumn{3}{|c|}{ Boundary condition: clamped-free } \\
\hline 1 & 450 & 260 \\
\hline 2 & 2795 & 1665 \\
\hline 3 & 7735 & 4700 \\
\hline \multicolumn{3}{|c|}{ Boundary condition: clamped-simply supported } \\
\hline 1 & 1935 & 1200 \\
\hline 2 & 6335 & 3835 \\
\hline 3 & 12130 & 7790 \\
\hline
\end{tabular}

Table 3: Experimentally identified natural bending frequencies of blades a and $b$.

\begin{tabular}{llll}
\hline Mode & \multicolumn{3}{l}{ Frequency $(\mathrm{Hz})$} \\
\hline \multicolumn{4}{l}{ Boundary condition: clamped-free } \\
1 & 445 & 270 & 475 \\
2 & 2800 & 1680 & 2990 \\
3 & 7845 & 4705 & 8370 \\
\hline \multicolumn{4}{l}{ Boundary condition: clamped-simply supported } \\
1 & 1960 & 1180 & 2090 \\
2 & 6355 & 3815 & 6780 \\
3 & 13260 & 7955 & 14145 \\
\hline
\end{tabular}

Table 4: Theoretical bending frequencies of blades a, $\mathrm{b}$ and c (Euler-Bernoulli beam model). 


\section{Methodology and tools for time-frequency decomposition of the experi- mental data}

\subsection{Fourier Transform (FFT and STFT)}

Given that blade-casing interactions and rubbing systems in general are associated with transient events that are relatively hard to predict, proper interpretation of experimental data would require tools that are adapted to time-frequency representation and capable of accurate event detection. The Fast Fourier Transform (FFT) and the associated Short-Time Fourier Transform (STFT) are commonly used in the field of tribology for this very purpose. The FFT can provide an accurate information about the frequencies involved but reveals nothing about their temporal distribution. The STFT corresponds to an FFT that is applied over a sweep signal window, whose width determines the time-frequency resolution. STFT results are generally plotted with time and frequency along the $\mathrm{x}$ - and $\mathrm{y}$-axis, respectively, while the amplitude of the resulting transform is represented with the help of a color map.

\subsection{Continuous Wavelet Transform (CWT)}

The method employed in this paper is the Continuous Wavelet Transform (CWT). The CWT is a projection of the signal onto a basis of complex and non-stationary functions (vs stationary for the STFT) called wavelets. The CWT is, by nature, a 2-D time-frequency decomposition, as opposed to the STFT, which is a translation of the 1-D FFT along time. The CWT decomposes the signal on scales that are fractional powers of two, whereas the STFT involves Fourier frequencies. The 2-D CWT representation is called a scalogram. Thanks to the non-stationary feature of the basis function, the CWT is capable of detecting events in transient signals such as discontinuities or singularities.

In the field of rotating machinery the CWT has been used to detect damage in rotors. For example, Sinou [21] proposed a methodology based on the CWT time-frequency decomposition of rotor displacement response in order to identify notched rotors. More specifically, the latter are identified through accurate time-frequency localization of the subharmonic resonance. This makes the CWT potentially interesting in terms of contact detection during blade-casing interactions. In a study by Al-Badour et al. [16], blade-stator rubbing experiments were analyzed using the CWT: after determining the scalogram, the authors searched for singularities by looking for abscissa corresponding to a convergence of wavelet modulus maxima on a fine scale. This method has the advantage of providing a mathematical description of singularities in the scalogram, but the plotted result does not seem to be accurate enough to localize contacts on the order of a millisecond (or less). As far as possible, singularities have been time-localized graphically in this paper.

The CWT was computed using a tool kit developed by Torrence and Compo [22] in Python (free library). The continuous wavelet transform $X$ of a discretized signal $\left(u_{n}\right)$ of size $N$ with mother wavelet $\psi$ is defined as [22]:

$$
X\left(n, s_{k}\right)=\sum_{i=0}^{N-1} u_{i} \psi^{*}\left[\frac{(i-n) \delta t}{s_{k}}\right]
$$

where $n$ is the time index, $s_{k}$ is the $k^{\text {th }}$ wavelet scale (expressed in seconds), $\psi^{*}$ is the complex conjugate of $\psi$ and $\delta t$ is the sampling period. 
The wavelet scales are defined as:

$$
s_{k}=s_{0} 2^{k \delta s}, k=0,1, \ldots, K
$$

where $s_{0}$ is the smallest resolvable scale, $K$ determines the largest scale and $\delta s$ is the scale parameter. $\delta s$ defines the number of wavelet scales used for the decomposition; the lower the value of $\delta s$ the better the scale resolution. However, $\delta s$ is limited by computer performances. Once $s_{0}$ and $\delta s$ are set, $K$ can be calculated [22].

Three mother wavelets, namely Paul, Derivative of Gaussian (DOG) and Morlet [23], were tested with different parameters. These mother wavelets were selected for their sinusoidale shapes. In the choice of wavelet, the wavelet function should reflect the features present in the signal to be analyzed [22]. In this study, strain signals (Fig. 3, 4 and 5) seem to be mainly composed of sinusoidal blade vibrations.

As a test, the different CWT were applied to a synthetized signal composed of frequencies within the [0-10 kHz] range, with fast transitions between frequencies (as assumed in the experimental data). For such a signal, Paul and DOG mother wavelets were found to have an insufficient scale resolution within the considered range. Then, considering the Morlet wavelet, parameter $p$ was chosen to have a reduced number of wavelet oscillations, which improves the time resolution. Thus, the best compromise between time and scale resolutions was the Morlet wavelet with $p=6$ :

$$
\psi(\eta)=\pi^{-1 / 4} e^{j p \eta} e^{-\eta^{2} / 2}
$$

where $\eta$ is a time to scale ratio (nondimensional time parameter), $j^{2}=-1$ and $p$ is the wavelet parameter, which defines the number of oscillations of the wavelet $(p=6)$. $\delta t$ was set to the sampling period of the signal and $\delta s=0.01$.

\subsection{From scalogram to spectrogram}

In the literature, CWTs are typically represented in the form of scalograms, i.e. with wavelet scales plotted along y-axis. However, this is impractical in our case for two reasons: first, one of the objectives of using the CWT here is to identify natural blade frequencies during blade-coating rubbing, but these frequencies are defined in the Fourier domain and cannot be identified directly from a scalogram; second, according to equation 2, wavelet scales have a non-linear distribution while the FFT and STFT provide a linear distribution of frequencies. For these reasons, the CWT in this paper has been represented in the form of a spectrogram, which is the usual form of an STFT. This required the following two steps:

1. conversion of scales to Fourier frequencies;

2. redistribution of the CWT along the y-axis in order to convert the non-linear distribution of frequencies into a linear one.

For the chosen parameters of the CWT and for $\mathrm{N}=2^{15}$ (signal size), the scales $s_{k}$ defined in equation 2 are shown in Fig. 8 (solid line). Given that the Morlet wavelet is a periodic function enveloped by a Gaussian, it is possible, for this mother wavelet, to write an analytical relation between Fourier frequencies and scales [24]:

$$
f_{k}=\frac{p+\sqrt{2+p^{2}}}{4 \pi s_{k}}
$$

where $p$ is the chosen wavelet parameter. 
The Fourier frequencies $f_{k}$ defined in equation 4 are shown in Fig. 8 (dotted line). The scales $s_{k}$ are defined over the $\left[s_{0}, s_{K}\right]$ scale band, where $s_{0}$, corresponding to the highest frequency in the Fourier domain, ensures that the Nyquist criterion is met, i.e.:

$$
s_{0}=\frac{\delta t\left(p+\sqrt{2+p^{2}}\right)}{2 \pi}
$$

where $\delta t$ is the data sampling period. $s_{K}$ is the largest scale (corresponding to the lowest Fourier frequency $f_{K}$ ) and is equal to the signal duration [22]:

$$
s_{K}=N \delta t
$$

where $N$ is the size of the signal. In this study, the relevant Fourier frequency band is $\left[f_{K}, f_{k_{10}}=10 \mathrm{kHz}\right]$ as indicated in Fig. 8. The corresponding scale band is $\left[s_{K}, s_{k_{10}}\right]$. $\delta s$ parameter value was set to 0.01 (section 4.2) in order to have approximatively 1000 scales in the $\left[s_{K}, s_{k_{10}}\right]$ scale range (Fig. 8), for a signal of $N=2^{15}$ points. This scales number was chosen to be on the same order of the frequencies number in a FFT (of same signal) over the $\left[0, f_{k_{10}}=10 \mathrm{kHz}\right]$ frequency band. This frequencies number is given by $N f_{k_{10}} \delta t$ where $\delta t=$ $3 \mu \mathrm{s}$.

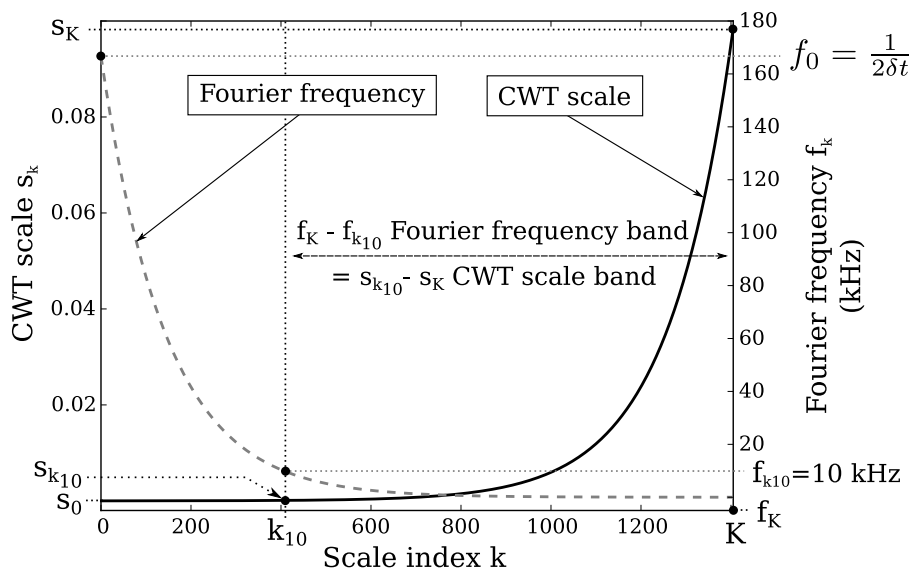

Figure 8: Scales versus Fourier frequencies for the Morlet mother wavelet $(\mathrm{p}=6)$.

The CWT of the blade strain $\varepsilon_{x x}$ recorded during experiment 2 is shown in Fig. 9. Frame A shows the raw signal, while frame $\mathrm{B}$ shows the real part of the $\mathrm{CWT}, \operatorname{Re}(X)$, as calculated according to equation 1 . Time is represented along the $\mathrm{x}$-axis of frames $\mathrm{A}$ and $\mathrm{B}$, while the scale index $k$ is represented along the $\mathrm{y}$-axis of frame B. The scales $s_{k}$ and the Fourier frequencies $f_{k}$ for the scalogram in frame B are plotted as non-linear distribution of frequencies in frame C. In order to obtain a linear representation of scales and Fourier frequencies along the y-axis, the function of two variables $X\left(n, f_{k}\right)$ ( $n$ is the time index, $f_{k}$ is the $k^{\text {th }}$ frequency) was distributed on a regular frequency grid. The distribution was processed with the interp function (function of interpolation) available in the NumPy library for Python [25]. Frame D shows the redistributed CWT, while frame E shows the corresponding scales and Fourier frequencies for the y-axis of the spectrogram obtained. One of the frequencies $f_{b}$ contained in the $\varepsilon_{x x}$ signal has been highlighted to better illustrate this scalogram-to-spectrogram conversion. 


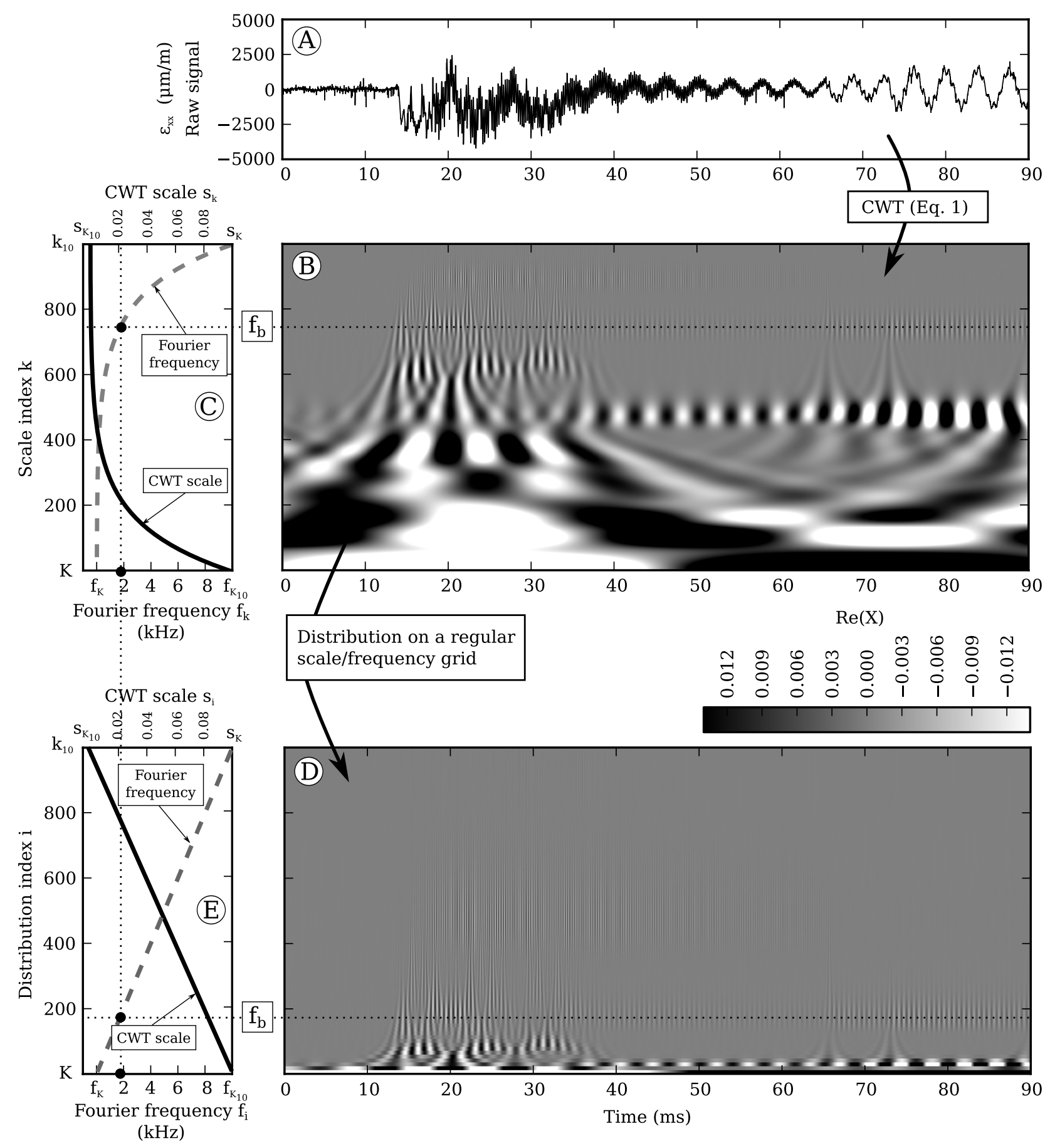

Figure 9: Spectrogram representation of CWT: A) blade strain $\varepsilon_{x x}$ in experiment 2 (raw signal), B) real part of CWT in scalogram representation C) scale and frequency distribution for scalogram B, D) real part of CWT in spectrogram representation, E) scale and frequency distribution for scalogram D. 


\subsection{Combined CWT-FFT decomposition of the signal}

This section aims to compare the CWT with the STFT. All CWTs are henceforth plotted in spectrogram form. Since the CWT and FFT are complex transforms, they can be decomposed into a real part and an imaginary part, or used with the modulus. In STFT spectrograms, the FFT modulus is usually plotted. Regarding calculation costs, as a comparison, for a $2^{15}$ point signal, with the above-mentionned parameters and with 4 Gb RAM, STFT is computed in $1 \mathrm{~s}$ vs $7 \mathrm{~s}$ for CWT. Both the STFT and the CWT are calculated over the complete Nyquist frequency band $\left[0-\frac{1}{2 \delta t} \mathrm{~Hz}\right]$. The CWT calculation cost above-mentionned does not include the interpolation to obtain the linear representation of frequencies (frame B to D in Fig. 9), which adds $6 \mathrm{~s}$ to the global cost. CWT has a greater calculation cost than STFT but remains reasonable using a standard computer.

Fig. 10 shows the time-frequency decomposition of the blade strain $\varepsilon_{x x}$ recorded during experiment 2 (frame A), represented using the STFT modulus (frame B) and then the CWT modulus (frame C). All three frames share the same time axis, while the STFT and CWT share the same frequency axis.

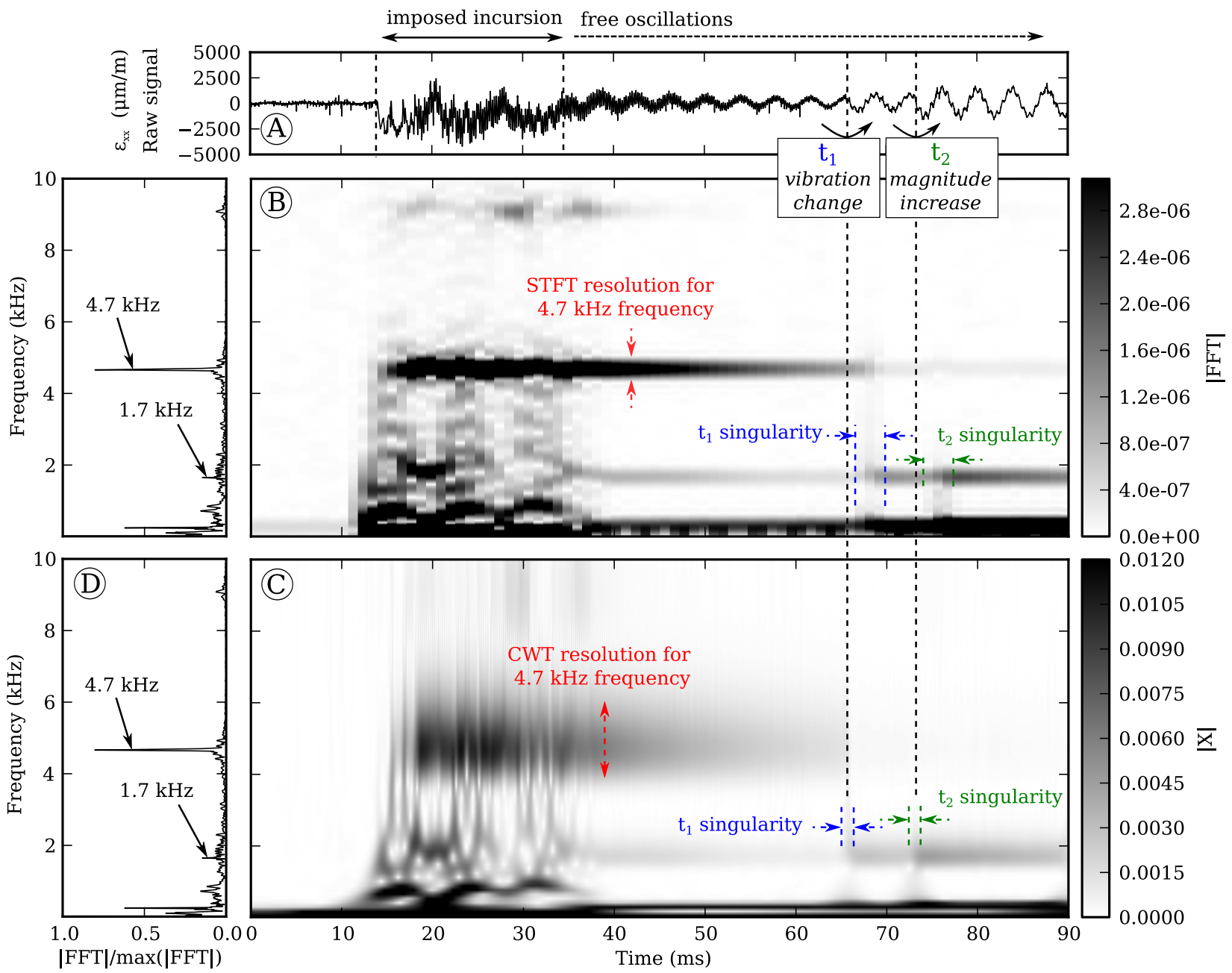

Figure 10: Comparison between STFT and CWT modulus for the time-frequency decomposition of the blade strain $\varepsilon_{x x}$ in experiment 2: A) raw signal, B) STFT modulus, C) CWT modulus, D) FFT modulus over the complete signal. 
The STFT was computed with a 5-ms-wide window and $80 \%$ overlap; contrary to standard pratice, the spectrogram was not interpolated along the time axis during plotting in order to represent the true time resolution. The observation of the raw strain signal during the free oscillations (frame A) shows two specific time instants $t_{1}$ and $t_{2}$ (marked with vertical dotted lines) that can be analyzed by means of STFT (frame B) and CWT (frame C). At time $t_{1}$, it is apparent in raw signal that the excited frequencies changed; at time $t_{2}$, the blade strain increased. Such changes or singularities are detected by spectrograms. In the STFT (frame B) vertical patterns are observed around $t_{1}$ and $t_{2}$ but with a delay of $3 \mathrm{~ms}$ and with $3 \mathrm{~ms}$ of uncertainty. The CWT (frame C) shows also vertical patterns but they are centered on times $t_{1}$ and $t_{2}$, with 1 ms of uncertainty. The delay observed with the STFT is due to the window width $(5 \mathrm{~ms})$. Reducing this window width would improve the time precision but would have no physical meaning, given the largest oscillations periods in the signal.

As suggested by the observation of the raw signal, the time instant $t_{1}$ is associated to a transition between frequencies which are both identified by STFT and CWT, but with a poor resolution (respectively 0.5 and 2 $\mathrm{kHz}$ ). In order to quantify accuratly these frequencies, the FFT spectrum of the signal is appended on the left of the spectrograms (frame D). Thanks to the spectrogram/FFT combination, it can be said that the vibration change occuring at time $t_{1}$ is due to a frequency transition from 4.7 to $1.7 \mathrm{kHz}$. In the next section, these frequencies will be compared to the modal analysis that was presented in section 3 .

A similar work was achieved considering the real part of the STFT and then the real part of the CWT (Fig. 11, frames B and D, respectively). In the case of the STFT, the time-frequency analysis was not improved by separating the real part. However, in the CWT spectrogram, the singularities occuring during the free oscillations give rise to curving lines crossing the low frequencies and converging, as highlighted in Fig. 11 , frame $\mathrm{C}$. The convergence points are centered on times $t_{1}$ and $t_{2}$, around $3 \mathrm{kHz}$. With this spectrogram, the time precision for singularity detection is evaluated graphically to $0.2 \mathrm{~ms}$. In CWT spectrogram (frame C), it should be noted that the oscillations between positive and negative values along the time axis, for low frequencies $(<2 \mathrm{kHz})$, have a physical meaning, since they are the temporal reflection of the signal frequencies.

Among CWT, STFT and FFT, there is no unique solution for a relevant time-frequency analysis. The STFT (using the modulus or the real part) fails in singularity detection because of time windowing (Fig. 10 and 11, frames B); the CWT (using the real part) shows the best precision for event detection (Fig. 11) but has a poor frequency resolution above $2 \mathrm{kHz}$. FFT offers the best frequency resolution but without temporal representation. In view of these considerations, a combined FFT-CWT representation is proposed and used in the next section. As shown in Fig. 11, the combination of frames A (raw signal), C (real part of the CWT, $\operatorname{Re}(X)$ ) and D (FFT modulus of the complete signal) provides a direct visualization of the signal, the excited frequencies with FFT precision, and their evolution during the experiment with CWT time precision. In addition, the CWT enables accurate localization of isolated contacts. 


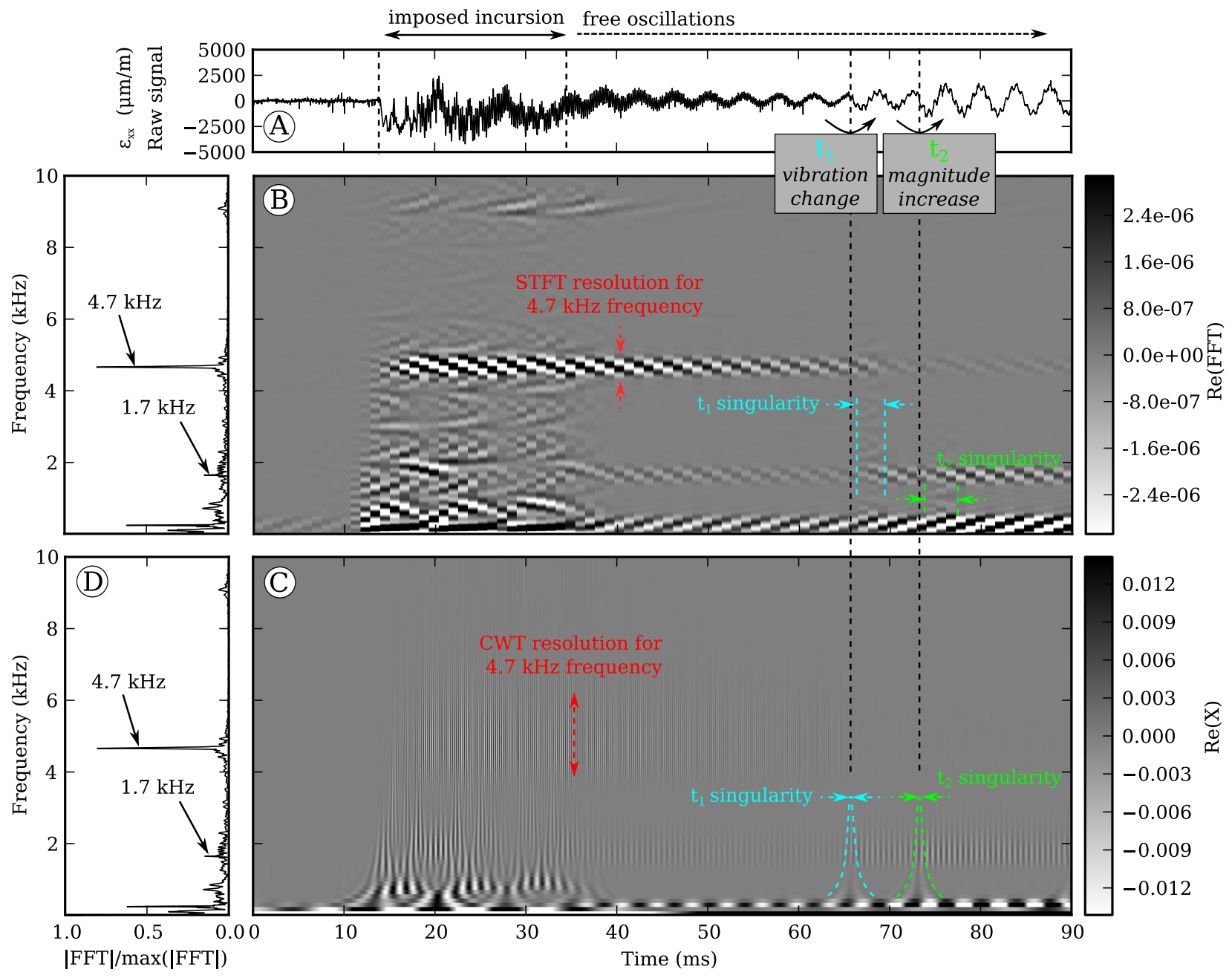

Figure 11: Comparison between the real parts of STFT and CWT for the time-frequency decomposition of the blade strain $\varepsilon_{x x}$ in experiment 2: A) raw signal, B) real part of STFT, C) real part of CWT, D) FFT modulus over the complete signal.

\section{Blade-coating interaction analysis}

Experiments 1, 2 and 3 presented in the first part of this paper were conducted with blades a, b and c respectively. The theoretical dynamic characteristics of these blades have been detailed by Baïz et al. in [10]. The theoretical natural frequencies are given in Table 4. The CWT spectrograms with juxtaposed FFT spectra of the blade strain $\varepsilon_{x x}$ are presented in Fig. 12, 13 and 14 for experiments 1, 2 and 3, respectively. This section aims to analyze the experiments based on these spectrograms and the images of the interaction zones captured at 4000 images per second. In this analysis of signals, a number of specific time instants (but non exhaustive) have been highlighted in order to help the interpretation of interactions. The objective is twofold: having a full understanding of the blade/abradable-coating interaction and to identify the active modes during rubbing. 

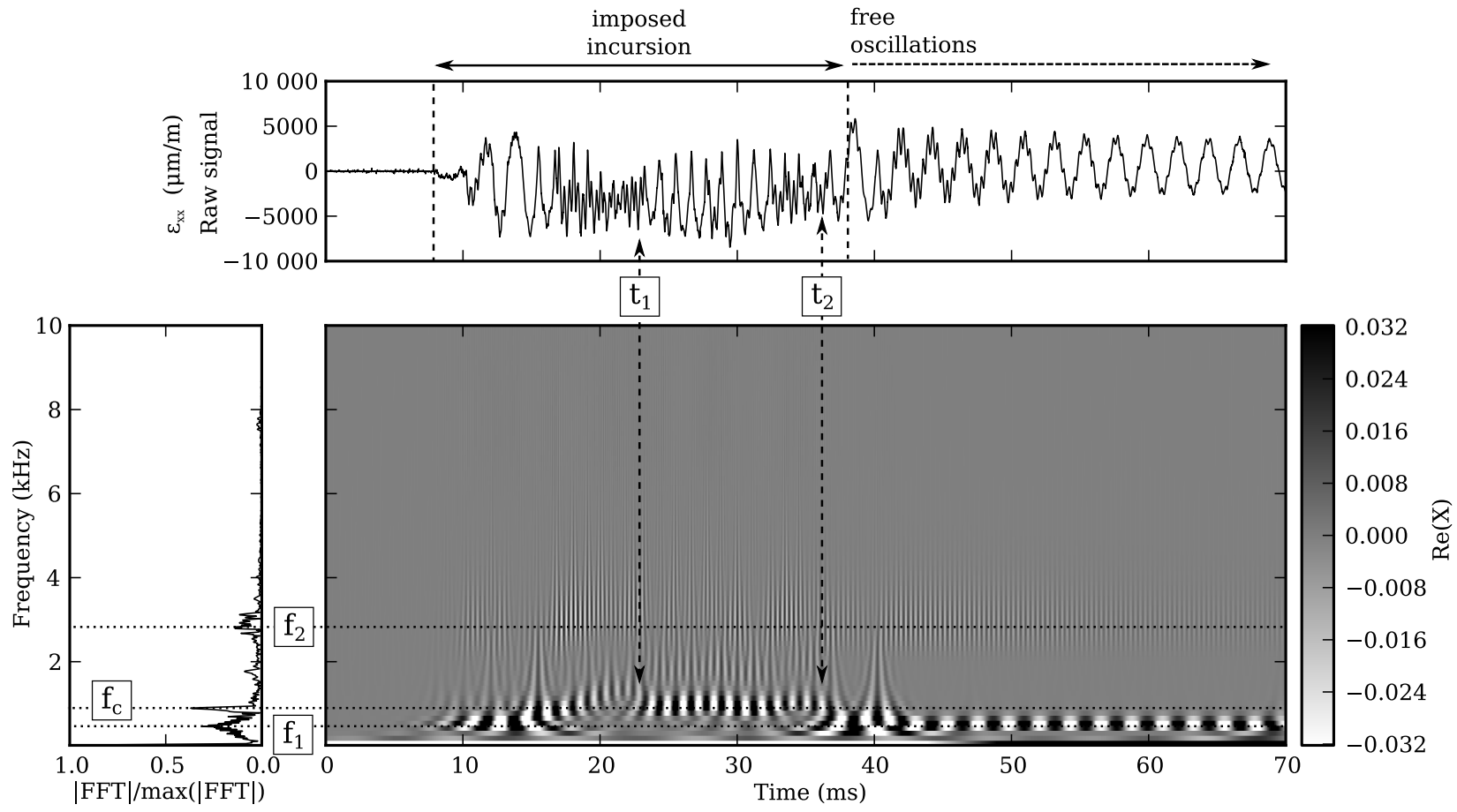

Figure 12: Time-frequency decomposition of blade strain $\varepsilon_{x x}$ in experiment 1.
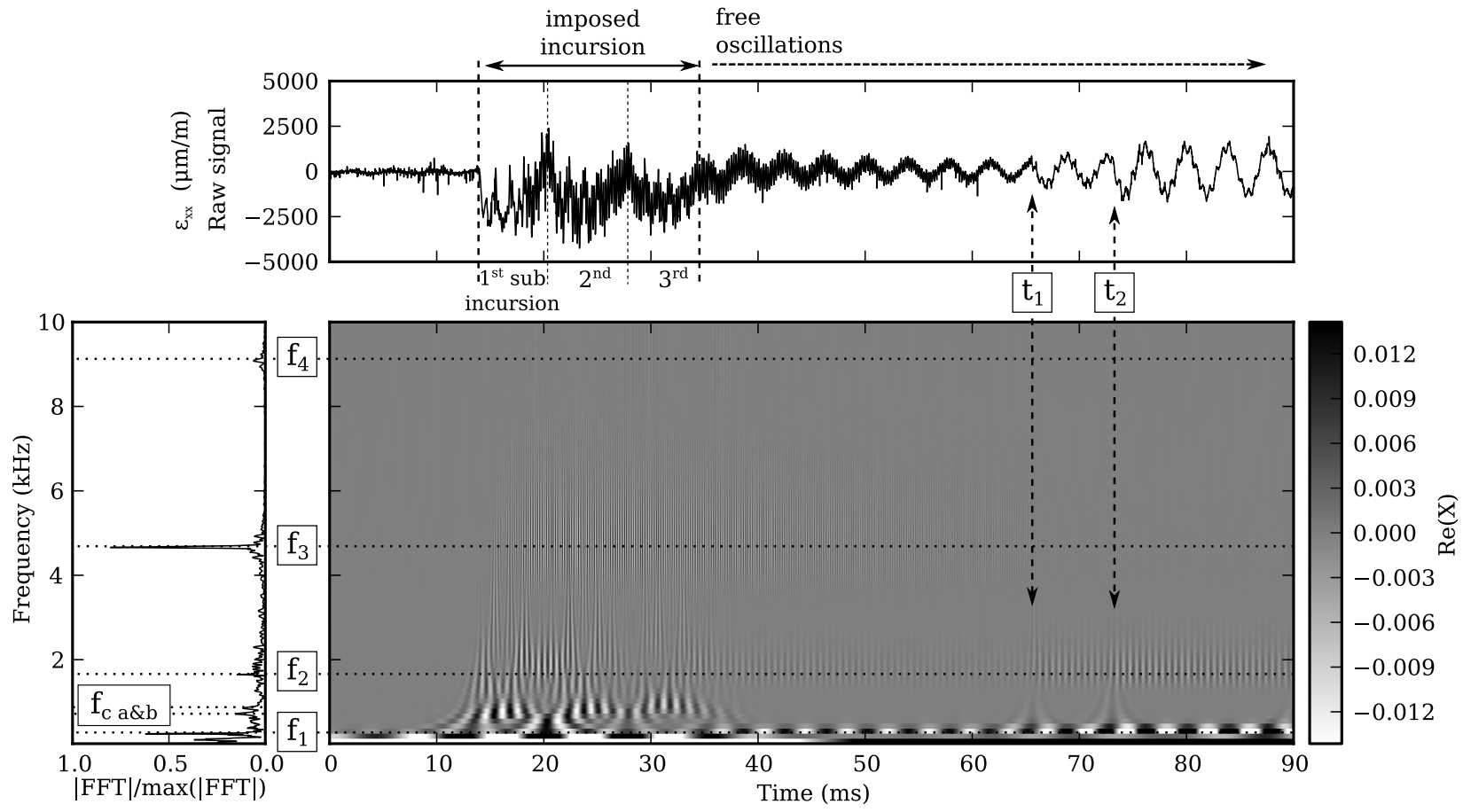

Figure 13: Time-frequency decomposition of blade strain $\varepsilon_{x x}$ in experiment 2 . 


\subsection{Friction-induced blade modes}

The frequencies contained in the blade strain $\varepsilon_{x x}$ are shown by the horizontal dotted lines in Fig. 12, 13 and 14. The frequencies labeled $f_{n}$ with $n \in \mathbb{N}$ are those that were identified as corresponding to the natural bending modes of the blades. In experiment $1, f_{1}$ and $f_{2}$ correspond to the first and second bending modes of the blade a in the clamped-free boundary conditions (Table 3). Similarly, in experiments 2 (Fig. 13) and 3 (Fig. 14), the frequencies $f_{n}, n \in \mathbb{N}$ are respectively the first four and three blade bending modes in the clamped-free boundary condition. No frequency corresponding to the clamped-simply supported boundary condition was found in any of the experiments. The reader may recall the starting assumption whereby interactions are associated with two alternating kinematic boundary conditions, namely the free blade tip and the simply-supported condition. However, the present analysis shows that this simply-supported boundary condition does not occur. This preliminary conclusion will be a major starting point for the modeling of the experiment.

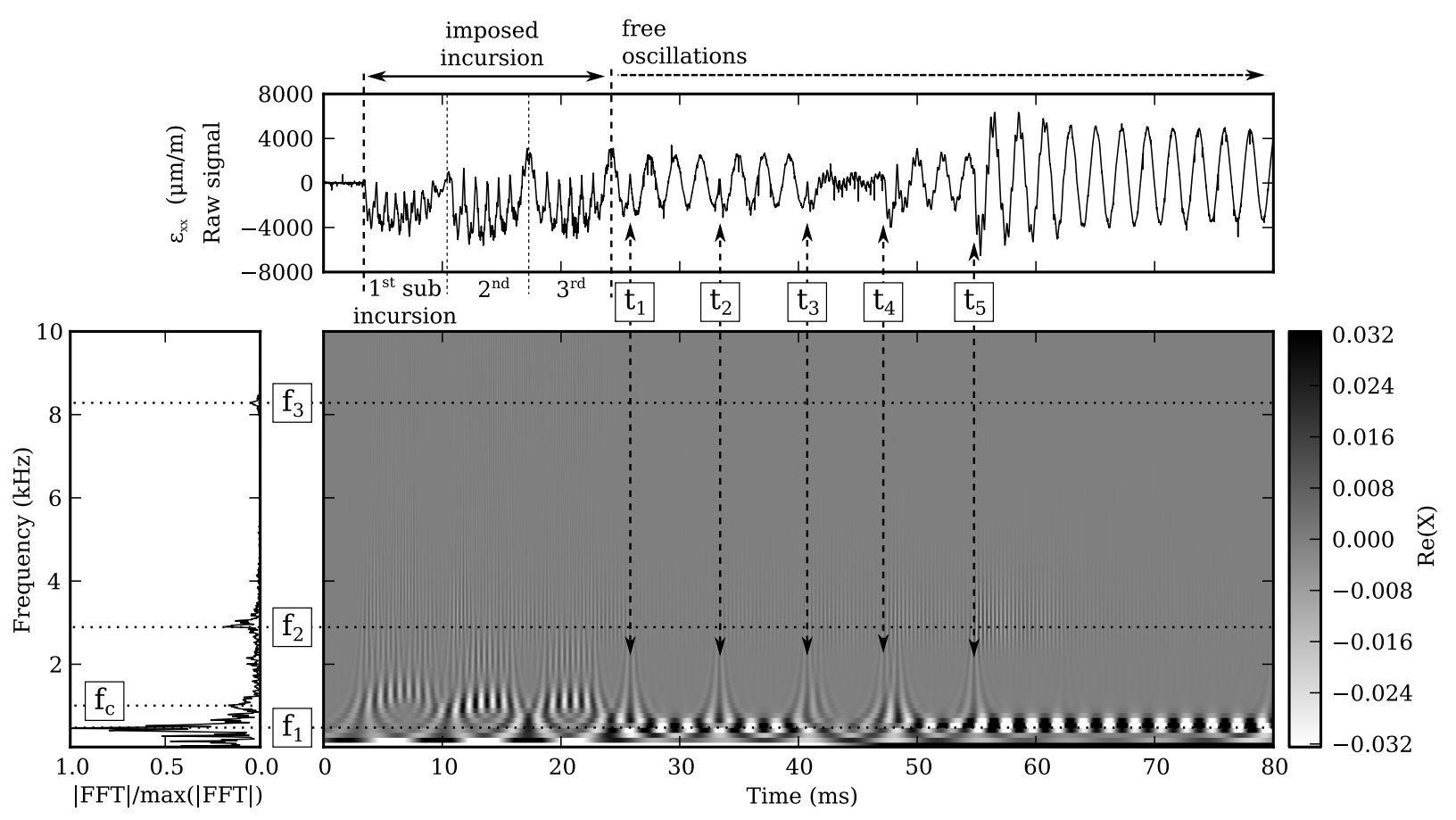

Figure 14: Time-frequency decomposition of blade strain $\varepsilon_{x x}$ in experiment 3 .

\subsection{Blade-coating bounces}

In the three experiments, the natural bending modes of the blades were not the only frequencies that were identified. Characteristic frequencies of the contact were also detected. These frequencies have been labeled as $f_{c}$ in Fig. 12 and 14 and $f_{c}^{a}, f_{c}^{b}$ in Fig. 13. As demonstrated in Fig. 15, $f_{c}$ frequencies were due to intermittent contacts between the blade tip and the abradable coating. In this figure, the CWT and the FFT were applied to the strain signal of experiment 3 over a time window centered on the $2^{\text {nd }}$ sub-incursion (cf. Fig. 6, [7-21 ms] time window). The time history at the beginning of the $2^{\text {nd }}$ sub-incursion has been detailed with the help of high-speed imaging, strain signal and CWT. Technical details on the high-speed imaging of the experiments have been provided by Baïz et al. in [10]. 


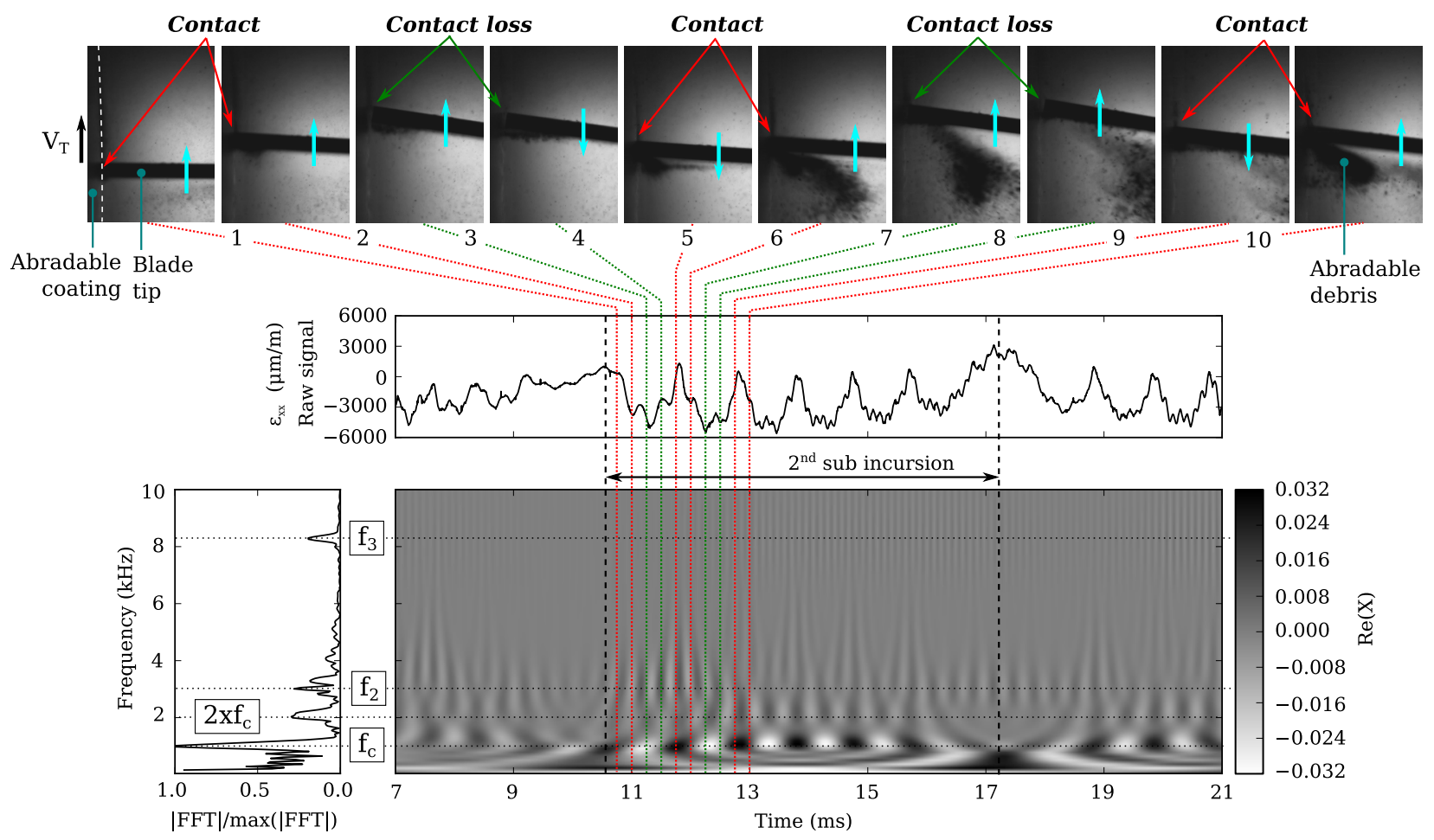

Figure 15: Time-frequency decomposition of the blade strain $\varepsilon_{x x}$ in experiment 3 over the [7-21 ms] time window correlated with high-speed imaging.

The images in Fig. 15 show that blade-coating contact losses occurred and were in phase with the white patterns in the spectrogram, at the frequency $f_{c}$. Regarding the FFT spectrum, which was computed over the [7-21 ms] time window with $71 \mathrm{~Hz}$ resolution (vs 0-80 ms in Fig. 14, with $12 \mathrm{~Hz}$ resolution), it is dominated by frequency $f_{c}(1000 \mathrm{~Hz})$ and indicates a new frequency $(2000 \mathrm{~Hz})$. According to the blade modes that were identified (Table 4), the $2000 \mathrm{~Hz}$ frequency may be either the first bending mode of blade $\mathrm{c}$ in the clamped-simply supported condition $(2090 \mathrm{~Hz})$, or the harmonic $2 x f_{c}$. In order to verify the nature of this frequency, the FFT was applied to the strain signal of experiment 1 (blade a) over the $t_{1}-t_{2}$ time window (13 ms, cf. Fig. 13), during which intermittent contacts were observed too. The corresponding FFT spectrum is shown in Fig. 16. Contact frequency $f_{c}$ was identified at $870 \mathrm{~Hz}$; the second frequency in the spectrum is of $1740 \mathrm{~Hz}$, which corresponds to the harmonic $2 x f_{c}$.

Therefore, the assumption of first blade bending mode in clamped-simply supported condition (cf. Table $4,1960 \mathrm{~Hz}$ ) can be excluded. In the three experiments, blade-coating bounces during short periods at frequencies $f_{c}$ ranging between 700 and $1000 \mathrm{~Hz}$ arised from the imposed incursions. In addition, the timefrequency analysis centered over these short periods indicated the presence of harmonics $2 x f_{c}$. Regarding the blade natural frequencies that were identified, they remained unchanged compared to the analysis achieved in section 5.1. 


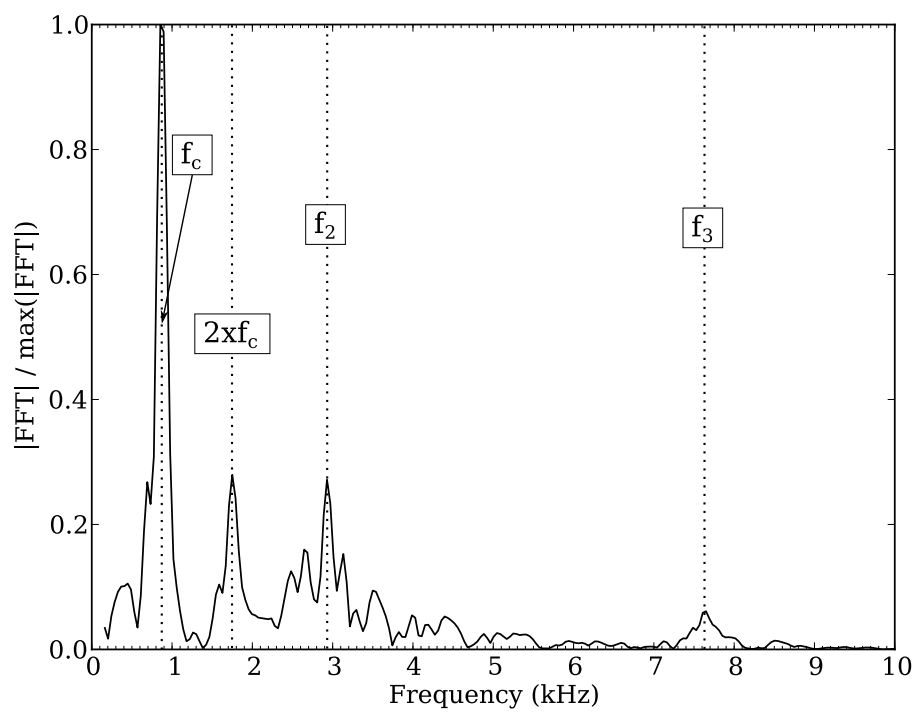

Figure 16: FFT spectrum of the blade strain $\varepsilon_{x x}$ in experiment 1 over the $\left[t_{1}-t_{2}\right]$ time window.

\subsection{Isolated blade-coating contact}

Blade-coating interaction is not just characterized by short periods of blade bouncing periods, but also by isolated contact occurences. In the present study, isolated contacts occurred during the free oscillations of the incursion cell at low values of apparent incursion $\left(D_{N}<100 \mu \mathrm{m}\right)$. Baïz et al. [10] conducted a preliminary analysis of the dynamic coupling resulting from such isolated events and identified two different situations, which they have referred to as type A and type B.

Type A coupling occurs when the direction of the blade deflection velocity is opposite to that of the tangential velocity of the abradable coating, $V_{T}$, as shown in Fig. 17a. In this configuration, i.e. when the upper surface of the blade is in compression $\left(\varepsilon_{x x}<0\right)$ and $\vec{V}_{T} \cdot \vec{y}>0$, the type A condition is defined by $\frac{\partial \varepsilon_{x x}}{\partial t}>0$. Type B coupling occurs when the direction of the blade deflection velocity is the same as that of the tangential velocity of the coating, $V_{T}$ (Fig. 17b). In this configuration $\left(\varepsilon_{x x}<0\right.$ and $\left.\vec{V}_{T} \cdot \vec{y}>0\right)$, the type B condition is defined by $\frac{\partial \varepsilon_{x x}}{\partial t}<0$. We may assume that contact leads to a decrease in blade vibrations during type A coupling but amplifies these vibrations in the presence of type B coupling.

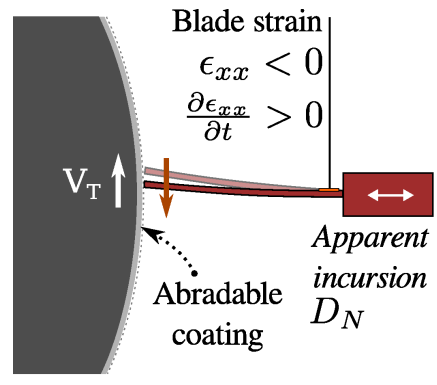

a) Type A coupling

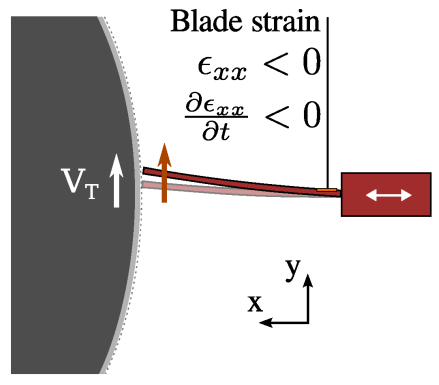

b) Type $B$ coupling

Figure 17: Dynamic blade-coating couplings for isolated contact. 
In experiment 2, the two isolated contact events detected via the CWT in experiment 2 at times $t_{1}$ and $t_{2}$ (Fig. 13) can be analyzed using this approach. At both $t_{1}$ and $t_{2}, \varepsilon_{x x}<0$ and $\frac{\partial \varepsilon_{x x}}{\partial t}<0$, which corresponds to the type $\mathrm{B}$ condition. The two contact occurences led to an increase in the magnitude of $\varepsilon_{x x}$, which confirms the previous assumption. It may also be observed that in this experiment, the excited blade modes differed depending on the nature of the contact. The free oscillations following the imposed incursion until time $t_{1}$ corresponded mainly to frequencies $f_{1}$ and $f_{3}$ (respectively first and third bending modes). The two isolated contact incidents at $t_{1}$ and $t_{2}$ shifted the highest mode from $f_{3}$ to $f_{2}$ (second bending mode) as shown in the spectrogram of Fig. 13.

The above observations were confirmed by comparison with high-speed imaging frames of the interaction. In experiment 3 (Fig. 14), type B coupling can be seen to have occurred at time $t_{5}$. Fig. 18a shows the images captured before, during and after $t_{5}$ in experiment 3 ; the time resolution between two consecutive images is $0.25 \mathrm{~ms}$. Image $i$ corresponds to the local maximum of $\varepsilon_{x x}$ just before $t_{5}\left(\varepsilon_{x x}=2500 \mu \mathrm{m} / \mathrm{m}\right.$, upper surface of the blade in tension). In the subsequent two images, the blade strain $\varepsilon_{x x}$ passes through zero (image $\left.i i\right)$ and becomes negative (image iii) during free oscillation. The type B condition is met in image iii and a single contact event occurs between images iii and $i v$. As the time interval between images is $0.25 \mathrm{~ms}$, contact of short duration can indeed take place between two consecutive frames. In image $v$, the blade deflection continues to increase while the (compressive) strain $\varepsilon_{x x}$ continues to decrease. Image vi does not come immediately after image $v$ and corresponds to the local maximum of $\varepsilon_{x x}$ just after $t_{5}\left(\varepsilon_{x x}=6000 \mu \mathrm{m} / \mathrm{m}\right.$, upper surface of the blade in tension). Fig. 18b shows the superimposition of images $i$ and $v i$, highlighting the effective amplification of blade vibration due to contact occuring at time $t_{5}$. It is important to note that no debris flow resulting from this kind of contact is visible in Fig. 18. Because of type B coupling, the abradable coating did not experienced any material loss, while the magnitude of the blade strain doubled.

Contact occuring at $t_{1}$ and $t_{2}$ in experiment 3 (Fig. 14) did not lead to any change in the blade strain

magnitude because at both times, it corresponded to local strain maxima $\left(\frac{\partial \varepsilon_{x x}}{\partial t} \approx 0\right)$, leading to the absence of coupling. A time $t_{3}$, contact with type A coupling occurred and stopped the blade vibration until $t_{4}$. The present analysis offers a new interpretation of the observations made by Baïz et al. [10], who reported three incidents of type A contact between times $t_{3}$ and $t_{4}$ in experiment 3 , that were concurrent with the cessation of blade vibrations and the absence of blade-coating interaction. Using the time-frequency decomposition, contacts are localized with fine precision and corroborated by high-speed imaging, which allows to interpret the experiments with confidence.

\subsection{Couplings between dynamics and wear}

During interactions, blade-coating contact events are of different natures. There is a strong correlation between blade dynamics and abradable coating wear. As observed in Fig. 18 and discussed previously, isolated blade contact events of type B did not affect the abradable coating, but can be critical for the blade integrity. The low apparent incursion $D_{N}$ that oscillates about zero enables the blade to oscillate about the zero-displacement position as well. In the event of a modal interaction between the blade vibration and the revolution speed of the abradable coating, successive contact occurences of type B could dangerously lead to an increase in the magnitude of blade vibration (blade divergence). Such modal interactions, showing blade divergent behavior, were reported in the litterature in the case of full-scale experiments $[15,12]$. 

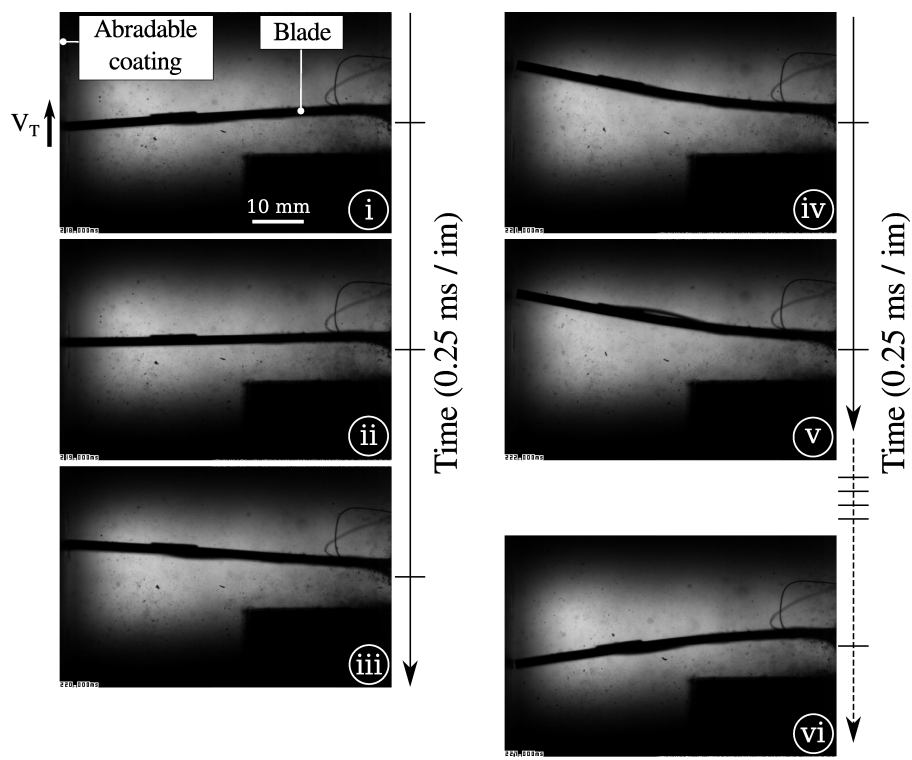

a) Contact scenario

(high-speed imaging, 4000 images per second)

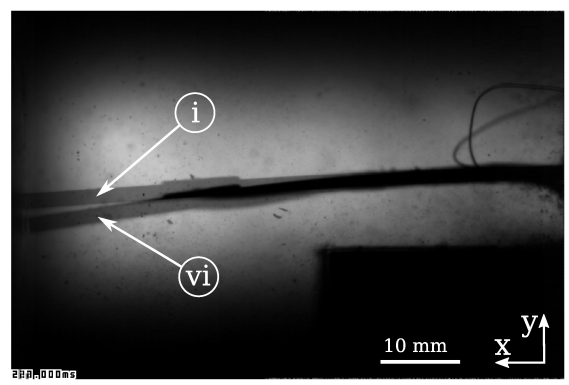

b) Blade vibration amplification

(superimposition of images $i$ and vi)

Figure 18: High-speed imaging of isolated blade-coating contact at time $t_{5}$ in experiment 3 .

By contrast, bouncing of the blade occurs with high apparent incursion (cf. 5.2) and the blade is forced to vibrate about a non-zero position. This situation is more critical with regard to the integrity of the abradable coating. Indeed, high-speed imaging shows significant abradable material loss, as depicted in Fig. 15 (experiment 3). Important ejection of abradable debris is visible during the second (images 5-6) and third (images 9-10) contact events. The first contact (images 1-2) produced a very small amount of debris. This difference within a period of bounces can be interpreted by means of the couplings described for isolated contact (Fig. 17). At the beginning of the $2^{\text {nd }}$ sub-incursion, and more specifically at the initiation of the first contact (image 1), the blade motion was such that $\frac{\partial \varepsilon_{x x}}{\partial t}<0$, which corresponded to type B coupling. But the second (images 5-6) and third (images 9-10) contact events were initiated when $\frac{\partial \varepsilon_{x x}}{\partial t}>0$, corresponding to type A coupling, and were associated to abradable material loss.

In the previous study by Baïz et al. [10], blade bounce periods were also correlated with wear marks on the abradable coating. These wear marks were found to be slightly asymmetrical along the blade width, suggesting that a running-in period would be necessary in future experiments. 
In the absence of running-in, contact conditions are not expected to be identical between successive experiments. Moreover, asymmetrical contact may be a source of blade excitation in torsion. In all three experiments, blade bending was analyzed by means of strain measurement along the blade centerline. It is worth nothing that blade torsion is very difficult to measure in this particular configuration. The blade torsional modes were identified through the experimental modal analysis (blade a: $4850 \mathrm{~Hz}$, blade b: 2960 $\mathrm{Hz}$ ). As expected, they were not detected in the strain gauge signal.

\section{Conclusions}

In this study, attention has been paid to the analysis of experimental blade/abradable-coating interaction data. The objectives were to identify the blade friction-induced vibrational modes, to localize the shortduration contacts and to highlight the couplings between blade vibration and abradable coating wear.

A time-frequency analysis of blade-coating interaction experiments, using the Continuous Wavelet Transform (CWT) and Fast Fourier Transform (FFT) concurrently, has been proposed. The CWT was chosen for its distinctive capabilities of time resolution and the detection of singularities induced by blade/abradablecoating contact. As opposed to the usual scalogram representation, the CWT was analyzed in the form of a spectrogram, so as to enable direct localization of excited Fourier frequencies. The latter were precisely quantified by means of FFT. The method has been described in the present paper and could be used in the analysis of blade-coating rubbing, whether in laboratory experiments or in full-scale tests, in which more complex vibrational modes are involved. More generally, this tool could be implemented for any analysis of fast and transient phenomena.

The time-frequency decomposition of the experimental blade strains has enabled to correlate the excited frequencies with the modal analysis of the blades. The excited vibrational modes were identified as corresponding to the first clamped-free bending modes, suggesting a slight influence of the contact stiffness on the blade-coating interaction. This observation, which was made for experiments with three different blades, provides a basis for modeling the interaction and estimating the force at the blade tip.

Two kinds of blade-coating rubbing were identified during the experiments: blade-coating bounces of short duration occuring at high apparent blade-to-coating incursion, and isolated contact occuring at very low apparent incursion. Bouncing of the blade was associated with vibrations about a non-zero position and significant abradable material loss. By contrast, isolated contact incidents were linked to very low levels of abradable material loss and blade vibrations about zero, whose amplitude could be reduced or significantly amplified depending on the dynamic coupling between the blade motion and the abradable coating.

\section{Acknowledgment}

This study was supported by SNECMA and received the financial support of the French Ministry of Higher Education and Research, both of whom are gratefully acknowledged. Thanks are also due to the International Campus on Safety and Intermodality in Transportation (CISIT), the Nord-Pas-de-Calais Region, the European Community, the Regional Delegation for Research and Technology, the Ministry of Higher Education and Research, and the National Centre for Scientific Research. The authors thank Jacques Charley (Arts et Métiers ParisTech Centre de Lille, LML) for his help with the modal analysis. 


\section{References}

[1] Millecamps, A., Brunel, J.-F., Dufrenoy, P., Garcin, F., and Nucci, M., 2009, "Influence of thermal effects during blade-casing contacts experiments", Proceedings of the ASME IDETC/CIE, San Diego, CA, Aug. 30-Sept. 2, ASME Paper No. DETC2009-86842, pp. 855-862.

[2] Sutter G., Philippon S. and Garcin F., 2006, "Dynamic analysis of the interaction between an abradable material and a titanium alloy", Wear, 261, pp. 686-692.

[3] Cuny M., Philippon S., Chevrier P. and Garcin F., 2011, "Etude expérimentale des interactions dynamiques aube/carter", Proceedings of 20e Congrès Français de Mécanique, France (in French).

[4] Stringer J. and Marshall M.B., 2012, "High speed wear testing of an abradable coating", Wear, 294-295, pp. 257-263.

[5] Fois, N., Stringer, J., and Marshall, M. B., 2013, "Adhesive transfer in aero-engine abradable linings contact", Wear, 304, pp. 202-210.

[6] Padova C., Barton J., Dunn M.G., Manwaring S., Young G., Adams M. and Adams M., 2005, "Development of an experimental capability to produce controlled blade tip/shroud rubs at engine speed", ASME J. Turbomach., 127(4), pp. 726-735.

[7] Padova C., Barton J., Dunn M.G. and Manwaring S., 2007, "Experimental results from controlled blade tip/shroud rubs at engine speed", ASME J. Turbomach., 129(4), pp. 713-723.

[8] Schmid, R.K., 1997, "New high temperature abradables for gas turbines", Ph.D. thesis, Swiss Federal Institute of Technology, Zurich, Switzerland.

[9] Bounazef, M., Guessasma, S., and Ait Saadi, B., 2004, "The wear, deterioration and transformation phenomena of abradable coating BN-SiAl-bounding organic element, caused by the friction between the blades and the turbine casing", Mater. Lett., 58, pp. 3375-3380.

[10] Baïz S., Fabis J., Boidin X. and Desplanques Y., 2013, "Experimental investigation of the blade/seal interaction", Proc. Inst. Mech. Eng. Part J.-J. Eng. Tribol., 227(9), pp. 980-995.

[11] Kascak A.F. and Tomko J.J., 1984, "Effects of different rub models on simulated rotor dynamics", NASA Technical Paper No. 2220, AVSCOM Technical Report No. 83-C-8.

[12] Jacquet-Richardet, G., Torkhani, M., Cartraud, P., Thouverez, F., Nouri Baranger, T., Herran, M., Gibert, C., Baguet, P., Almeida, P., and Palatan, L., 2013, "Rotor to stator contacts in turbomachines. Review and application", Mech. Syst. Signal Proc., 40, pp. 401-420.

[13] Johnston R.E., 2011. "Mechanical characterisation of AlSi-hBN, NiCrAl-Bentonite, and NiCrAlBentonite-hBN freestanding abradable coatings", Surf. Coat. Technol., 205, pp. 3268-3273.

[14] Krajcin, I., and Söffker, D., 2003, "Model-based estimation of contact forces in rotating machines", Proceedings of 4th IMACS Symposium on Mathematical Modeling, Vienna, Austria.

[15] Batailly, A., Legrand, M., Millecamps, A., and Garcin, F., 2012, "Numerical- experimental comparison in the simulation of rotor/stator interaction through blade-tip/abradable coating contact", ASME J. Eng. Gas Turbines Power, 134(8).

[16] Al-Badour F., Sunar M. and Cheded L., 2011, "Vibration analysis of rotating machinery using timefrequency analysis and wavelet techniques", Mech. Syst. Signal Proc., 25, pp. 2083-2101. 
[17] Laverty W.F., 1982, "Rub energetics of compressor blade tip seals", Wear, 75, pp. 1-20.

[18] Petitniot J-L., Des Rochettes H-M. and Leconte P., 2002. "Experimental assessment and further development of amplified piezo actuators for active flap devices", Proceedings of the 8th International Conference on New Actuators, ACTUATOR 2002, Germany.

[19] Wolak J., Emery A.F., Etemad S. and Choi S.R., 1984, "Blade tip geometry - A factor in abrading sintered seal material, ASME J. Tribol., 106(4), pp. 527-533.

[20] Olympio R.K., Poulin-Vittrant G., 2011, "A honeycomb-based piezoelectric actuator for a flapping wing MAV", Proc. SPIE, 7977, 79771U.

[21] Sinou J.J., 2009, "An experimental investigation of condition monitoring for notched rotors through transient signals and wavelet transform", Exp. Mech., 49, pp. 683-695.

[22] Torrence C. and Compo G.P., 1998, "A pratical guide to wavelet analysis", Bull. Amer. Meteorol. Soc., 79, pp. 61-78.

[23] Farge M., 1992, "Wavelet transforms and their applications to turbulence", Annu. Rev. Fluid Mech., 24, pp. 395-457.

[24] Meyers S.D., Kelly B.G., O’Brien J.J., 1993, "An introduction to wavelet analysis in oceanography and meteorology: with application to the dispersion of Yanai Waves", Mon. Wea. Rev., 121, pp. 2858-2866.

[25] The Scipy Community, 2013, "NumPy Reference", http://docs.scipy.org/doc/numpy/reference. 